\title{
The Role of Munc18-1 and Its Orthologs in Modulation of Cortical F-Actin in Chromaffin Cells
}

\author{
Julia Kurps • Heidi de Wit
}

Received: 28 December 2011 / Accepted: 9 April 2012 /Published online: 26 April 2012

(C) The Author(s) 2012. This article is published with open access at Springerlink.com

\begin{abstract}
Munc18-1 was originally described as an essential docking factor in chromaffin cells. Recent findings showed that Munc18-1 has an additional role in the regulation of the cortical F-actin network, which is thought to function as a physical barrier preventing secretory vesicles from access to their release sites under resting conditions. In our review, we discuss whether this function is evolutionarily conserved in all Sec1/ Munc18-like (SM) proteins. In addition, we introduce a new quantification method that improves the analysis of cortical filamentous actin (F-actin) in comparison with existing methods. Since the docking process is highly evolutionarily conserved in the SM protein superfamily, we use our novel quantification method to investigate whether the F-actin-regulating function is similarly conserved among SM proteins. Our preliminary data suggest that the regulation of cortical F-actin is a shared function of SM proteins, and we propose a way to gain more insight in the molecular mechanism underlying the Munc18-1-mediated cortical F-actin regulation.
\end{abstract}

Keywords Docking $\cdot$ Exocytosis $\cdot$ Chromaffin cell $\cdot$ Munc18 $\cdot$ Syntaxin- $1 \cdot$ F-actin

Abbreviations
ER $\quad$ Endoplasmatic reticulum
F-actin
Filamentous actin

J. Kurps $\cdot$ H. de Wit $(\bowtie)$

Department of Functional Genomics and Clinical Genetics, Center for Neurogenomics and Cognitive Research, Neuroscience Campus Amsterdam, VU University Amsterdam and VU

University Medical Center,

De Boelelaan 1085,

1081 HV Amsterdam, The Netherlands

e-mail: h.de.wit@vu.nl

$\begin{array}{ll}\text { LDCV } & \text { Large dense-core vesicle } \\ \text { PFA } & \text { Paraformaldehyde } \\ \text { PKC } & \text { Protein kinase C } \\ \text { ROI } & \text { Region of interest } \\ \text { SM } & \text { Sec1/Munc18-like } \\ \text { SNARE } & \text { Soluble } N \text {-ethylmaleimide-sensitive } \\ & \text { factor attachment receptor } \\ \text { TGN } & \text { Trans-Golgi-network }\end{array}$

\section{Role of Munc18-1 in Docking in Chromaffin Cells}

Regulated exocytosis of large dense-core vesicles (LDCV) is an essential process in chromaffin cells. Here, hormones and neuropeptides, which are stored in LDCVs, are released into the bloodstream. The initial step of vesicle secretion is the morphological docking of LDCVs to the plasma membrane, which is followed by priming and finally fusion of the vesicles. One protein family which is known to be essential for docking and fusion is the highly evolutionary conserved Sec1/Munc18-like (SM) protein family. The absence of Sec1, the Munc18-1 ortholog in yeast (Saccharomyces cerevisiae), leads to a secretion defect and to accumulation of secretory vesicles near fusion sites (Novick et al. 1981; Tschopp et al. 1984). Similarly, Rop (Sec1 ortholog in Drosophila melanogaster) and Unc18 (Sec1 ortholog in Caenorhabditis elegans) null mutants show a reduction of docked secretory vesicles at their release sites (Schulze et al. 1994; Weimer et al. 2003). The first proteins that were shown to be essential for the docking of secretory vesicles in mammals were Munc18-1 (Voets et al. 2001) and syntaxin-1 (De Wit et al. 2006). Both proteins and their essential role in the docking process are highly conserved from yeast to mammals. 
The nature of the interaction of syntaxin-1 and Munc18-1 is complex, since Munc18-1 can bind syntaxin-1 in two distinct modes. Munc18-1 can either bind the "open" syntaxin-1 in the assembled soluble $N$-ethylmaleimide-sensitive factor attachment receptor (SNARE) complex or the "closed" conformation of isolated syntaxin-1 (Pevsner et al. 1994; Dulubova et al. 2007; Khvotchev et al. 2007; Burkhardt et al. 2008; Gerber et al. 2008). The two distinct binding modes reflect distinct functions of Munc18-1. Two recent findings support the hypothesis that the binding of Munc18-1 to the closed conformation is responsible for the docking mechanism: (1) expression of an open syntaxin-1 mutant which only allows N-terminal interaction with Munc18-1 in an assembled SNARE complex showed a severe docking phenotype (Gerber et al. 2008) and (2) the robust docking phenotype in Munc18-1 null chromaffin cells was partially rescued when a Munc18-1 mutation, which is known to perturb the binding with the "closed" syntaxin-1 conformation, was expressed (De Wit et al. 2009). Those findings led to the conclusion that the binding of Munc18-1 to the "closed" conformation of syntaxin-1 is the functional interaction involved in the docking process, whereas the binding of Munc18-1 to the "open" syntaxin-1 in the assembled SNARE complex seems to be essential for later exocytosis steps such as fusion (Dulubova et al. 2007; Khvotchev et al. 2007; Barclay 2008; Burkhardt et al. 2008).

According to the current docking model obtained from electron microscopy studies on adrenal chromaffin cells from genetically modified mouse embryos, four proteins are involved in the formation of the minimal docking machinery. Those four proteins are syntaxin-1, Munc18-1, synaptosomal-associated protein 25 (SNAP-25), and synaptotagmin-1. The initial step of the vesicle docking is the formation of a 1:1 acceptor complex at the target membrane, containing the target soluble $N$-ethylmaleimide-sensitive factor attachment receptors' (t-SNAREs) syntaxin-1 and SNAP-25 (De Wit et al. 2009). Munc18-1 stabilizes this acceptor complex probably via binding to syntaxin-1. Recent findings showed that the vesicular protein synaptotagmin-1 binds to the acceptor complex and thereby anchors secretory vesicles to their docking sites at the plasma membrane (Söllner et al. 1993; Schiavo et al. 1997; Chieregatti et al. 2002; Rickman et al. 2004; De Wit et al. 2009). It is now widely accepted that the interaction of Munc18-1 with the "closed" syntaxin-1 conformation is essential for the docking process, whereas its binding to the "open" conformation seems to be involved in a suggested postdocking role of Munc18-1. This function of Munc18-1 will not be discussed here. For detailed reviews and the molecular mechanism underlying the role of Munc18-1 in the docking process in adrenal chromaffin cells, see Verhage and Sørensen (2008) and De Wit (2010a, b).

\section{Role of Cortical F-Actin in Regulated Secretion in Chromaffin Cells}

In addition to the minimal docking machinery (syntaxin-1, SNAP-25, synaptotagmin-1, and Munc18-1), the dense cortical network of filamentous actin (F-actin) underneath the plasma membrane was shown to mediate regulatory secretion in chromaffin cells (Aunis and Bader 1988; Trifaró et al. 1992). Since stimulation of chromaffin cells by high $\mathrm{K}^{+}$, phorbol esters, or nicotine resulted in a decrease in the integrity of the cortical F-actin network and an enhanced release of hormones and neuropeptides, it is suggested that this network forms a physical barrier for secretory vesicles (Trifaró et al. 1992). Under resting conditions, the F-actin network is highly polymerized and secretory vesicles cannot reach the plasma membrane, whereas stimulation leads to a depolymerization of the cortical F-actin, so secretory vesicles gain access to their release sites (Vitale et al. 1995). Since the known regulatory mechanisms, including essential proteins that control cortical F-actin dynamics, were the topic of several earlier reviews (Doussau and Augustine 2000; Trifaró et al. 2000; Trifaró et al. 2008), they will not be discussed here. However, the analysis methods which were used to access alterations in the cortical F-actin network will be shortly discussed. In the first studies, populations of neuroendocrine cells were classified according to the appearance of the rhodaminephalloidin staining of the cortical F-actin. Here, it was distinguished whether the cortical staining of single cells was continuous or composed of discontinuous patches and the changes in the F-actin network were presented as the percentage of cells with a discontinuous staining (Trifaró et al. 1992). Another method used alterations in the total intensity of the cortical fluorescence of the rhodamine-phalloidin staining as a measure for changes in the cortical F-actin (Doreian et al. 2008). Both methods focus on the overall $\mathrm{F}$-actin content of chromaffin cells and on the changes during stimulations or manipulations. However, for our observations, we were interested in the subcellular localization of F-actin patches along the plasma membrane and, as such, in a more precise quantification of the cortical F-actin network.

\section{Quantification of Cortical F-Actin in Chromaffin Cells}

In order to describe our observation of Munc18-1-dependent $\mathrm{F}$-actin regulation in detail, a reliable F-actin quantification method was required. Therefore, we developed an algorithm, which is performed in the image analysis program ImageJ and which enables us to quantify the alterations in cortical F-actin under various conditions. We use confocal microscopy images of fixed chromaffin cells which are stained with rhodaminephalloidin to visualize the cortical F-actin network underneath 
the plasma membrane (Fig. 1a, e, f). By using a process called polar transformation, the circular signal (Fig. 1a, b) is translated into a rectangular signal (Fig. 1c), which simplifies the threshold-based detection of the region of interest. For the polar transformation, the program first determines the center of the cell and generates a line from this point to the edge of the image. The number of pixels along the line depends on the size of the image. This step is repeated 360 times, with every new line being generated in an angle of $1^{\circ}$ from the previous line (Fig. 1b). The 360 lines, covering all pixels in the original image, form a new, transformed image (Fig. 1c). Subsequently, the imageJ analysis program automatically determines the right (extracellular) border of the cortical F-actin network, based on a threshold, which is dependent on the intrinsic image properties. The left (intracellular) border of the F-actin network is fixed as 40 pixels left from the right border (Fig. 1d). This measure was determined manually, since the automatic detection of the intracellular border is difficult, due to intracellular staining. The choice for the width of 40 pixels for the region of interest (ROI) is based on observations of a great amount of chromaffin cells, showing that the rhodamine-phalloidin-based signal does not extend this value. After the ROI is automatically determined, two output sheets are generated. One includes intensity values of all pixels in the ROI, and the other one contains the average signal intensity of all 360 lines as well as their thickness and density. For the described calculations, only pixels with intensity values above the automatically determined threshold are used.

Our new quantification method enables us to characterize the alterations in the cortical F-actin network due to the absence or presence of Munc18-1 in much more detail than in our previous study (Toonen et al. 2006). In Fig. 1e, f, typical examples of the F-actin network in Munc18-1 wild type and Munc18-1 null chromaffin cells are shown, clearly indicating that the absence of Munc18-1 leads to a thicker cortical F-actin network. This observation is clearly detectable
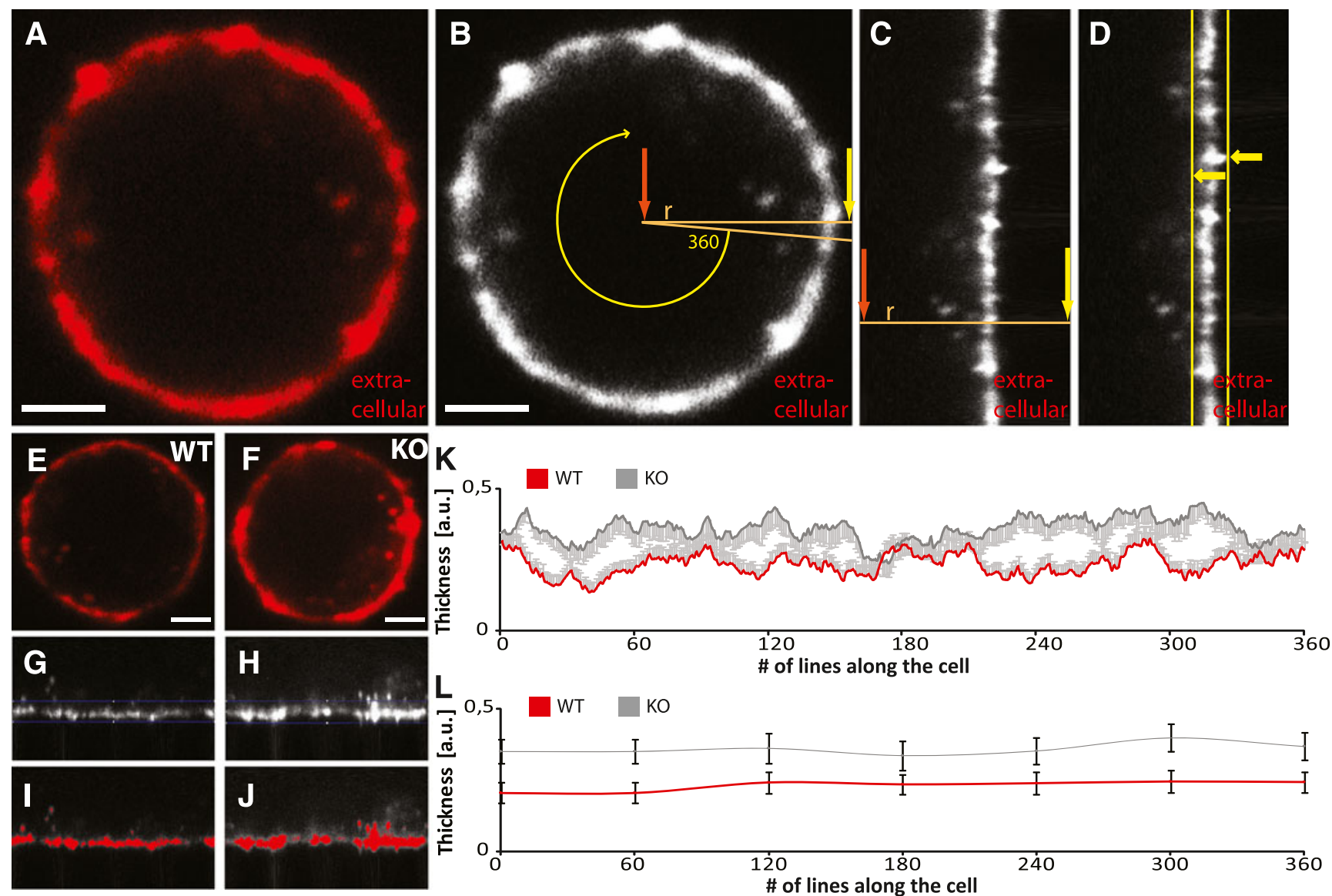

Fig. 1 Cortical F-actin quantification and alterations in thickness of cortical F-actin network due to absence of Munc18-1. a Cortical F-actin in chromaffin cell (fixed with $4 \%$ PFA at DIV3), stained with rhodamine-phalloidin and imaged with confocal microscopy. b Visualization of polar transformation of the rhodamine-phalloidin signal. $\mathbf{c}$ Rectangular signal after polar transformation. d Automatic, threshold-based definition of region of interest. e, f Cortical F-actin in Munc18-

1 wild type and Munc18-1 null chromaffin cell. g, h Automatically defined region of interest of $\mathbf{e}$ and $\mathbf{f}$. $\mathbf{i}$, j Pixels with intensity values above threshold of $\mathbf{g}$ and $\mathbf{h}$. $\mathbf{k}$ Quantification of cortical Factin thickness and comparison between Munc18-1 wild type ( $n=$ $25)$ and Munc18-1 null $(n=25)$ chromaffin cells. I Binned (bin size $=60$ values) thickness values of $\mathbf{k}$. Scale bars, $2 \mu \mathrm{m}$ 
in the transformed images (Fig. 1g, h) and reflected by the visualization of all pixels with intensity values above threshold, which are marked in red in Fig. 1i, j. The quantification of the cortical F-actin in populations of Munc18-1 wild type $(n=25)$ and Munc18-1 null $(n=25)$ chromaffin cells is shown in Fig. 1k. Here, the thickness of the cortical F-actin network is displayed for every line of the transformed image. The thickness is calculated as the sum of all pixels with an intensity value above the threshold divided by 40 , which determines the maximal number of pixels in one line of the region of interest. In order to show the increased thickness of the F-actin in Munc18-1 null cells even clearer, the thickness values were averaged in bins of 60 values (Fig. 11). Since cell culture, fixation, immunocytochemical processes, and the image acquisition are highly standardized and identical for both genotypes, the observed effect is solely dependent on the presence of Munc18-1.

\section{Cortical F-Actin Regulation: Conserved Function of SM Proteins?}

In order to clarify the role of Munc18-1 in the regulation of cortical F-actin in chromaffin cells, the evolutionary conservation of this process was questioned. Since actin is also highly conserved during evolution, there is an indication that actin-regulating functions and underlying mechanisms are also conserved during evolutionary development (Bhagavathi and Malathi 1996). Furthermore, the function of Munc18-1 in the docking process is highly evolutionary conserved (Schulze et al. 1994; Weimer et al. 2003, Toonen et al. 2006). Therefore, the question arose whether the F-actin-regulating function of Munc18-1 is similarly conserved and whether other members of the SM protein family can regulate the cortical F-actin in chromaffin cells in the same way as Munc18-1.

The family of SM proteins consists of four subfamilies, which were defined according to their function in intracellular vesicle-trafficking processes (Fig. 2a).

Seclp Family The Sec1 family is highly evolutionarily conserved, and its members are known to be involved in exocytosis events. The Sec1 family includes the yeast (S. cerevisiae) protein Sec1p as well as its homologs in D. melanogaster, Rop, and in C. elegans, Unc18. The mammalian Munc18 isoforms Munc18-1, Munc18-2, and Munc18-3 are also members of the Sec1 family. Munc18-1 is known to be essential for docking of secretory vesicles to their target membrane but is also believed to have a function in the priming step (Gulyás-Kovács et al. 2007). Munc18-1 was shown to bind the syntaxin isoforms syntaxin-1, syntaxin-2, and syntaxin-3 (Toonen and Verhage
2003), and it is known that the SM protein binds syntaxin in the "closed" formation in the docking mechanism (De Wit 2010a, b). However, Munc18-1 can bind syntaxin in the "open" formation as well (Dulubova et al. 1999). This binding mode is believed to be involved in events downstream of docking (De Wit 2010a, b). The Munc18 isoforms Munc18-2 and Munc18-3 show lower expression in neuroendocrine cells (Hata and Südhof 1995; Tellam et al. 1995). Like Munc18-1, Munc18-2 shows a high affinity for syntaxin-1, syntaxin-2, syntaxin-3 and Munc18-3 shows a high affinity for syntaxin-2 and syntaxin-4 (Hata and Südhof 1995; Tellam et al. 1997).

VPS45p Family The VPS45 family contains vacuolar proteins and is important for the regulation of endosomal trafficking (Tellam et al. 1997). In yeast, VPS45p binds to the syntaxin Tlg2p, which plays an essential role in the vesicle transport between the trans-Golgi network (TGN) and early endosomes (Dulubova et al. 2002). VPS45p binds the conserved N-terminal sequence of Tlg2. It was recently discovered that VPS45p has an additional binding site, where Tlg2p in its "closed" formation can be bound. This might result in a competition between the N-terminal Tlg2 $p$ peptide and "closed" $T \lg 2 p$, and therefore, a regulatory mechanism for the SM protein-syntaxin interaction was suggested by the authors (Furgason et al. 2009). VPS45 homologs in D. melanogaster and mammals were also described. The mammalian homolog VPS45 binds to syntaxin-16, which is a homolog of Tlg2p and forms a SNARE complex with syntaxin- 6 and Vti 1a (Dulubova et al. 2002). The VPS45-syntaxin-16 interaction was shown to be involved in TGN transport, leading to the conclusion that the mechanism of vesicle trafficking between the TGN and early endosomes is highly conserved (Bassham et al. 2000; Struthers et al. 2009). VPS45p was also found to participate in late-endosomal vesicle transport, which is dependent on the syntaxin Pep12p. Interestingly, until now, no direct binding between Pep12p and VPS45p was observed (Webb et al. 1997).

Sly1p Family Members of the Sly 1p family are hydrophobic proteins, which regulate vesicle trafficking between the endoplasmic reticulum (ER) and the Golgi network as well as the retrograde transport back to the ER ( $\mathrm{Li}$ et al. 2005). Furthermore, a Sly1p function in intra-Golgi transport mechanisms was described. Sly1 binds to an evolutionary conserved N-terminal peptide motif of the Golgi t-SNARE Sed5 and the ER t-SNARE Ufe1 in yeast (Søgaard et al. 1994). More recent findings showed that the binding of Sly 1 to Sed5 enhances the formation of the trans-SNARE complex (Kosodo et al. 2002). Noteworthy, the mammalian Sly1 ortholog binds to the same N-terminal peptide motif of syntaxin-5 and syntaxin-18 in vertebrates (Yamaguchi et al. 2002). 
A

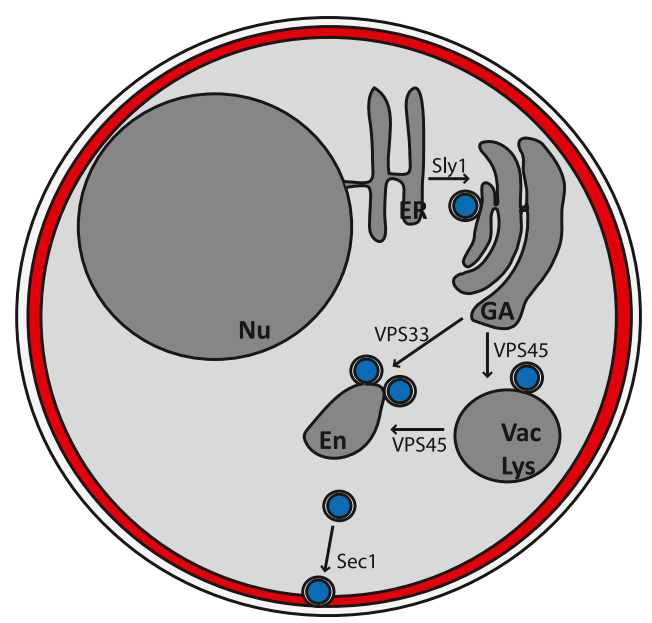

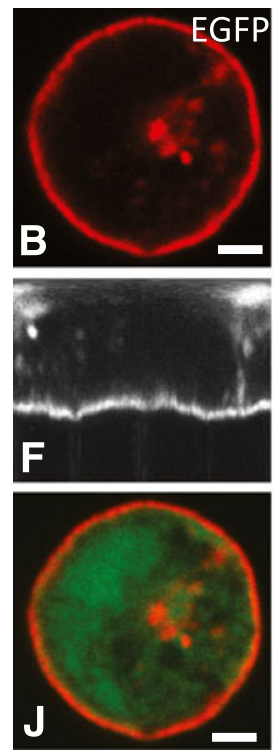
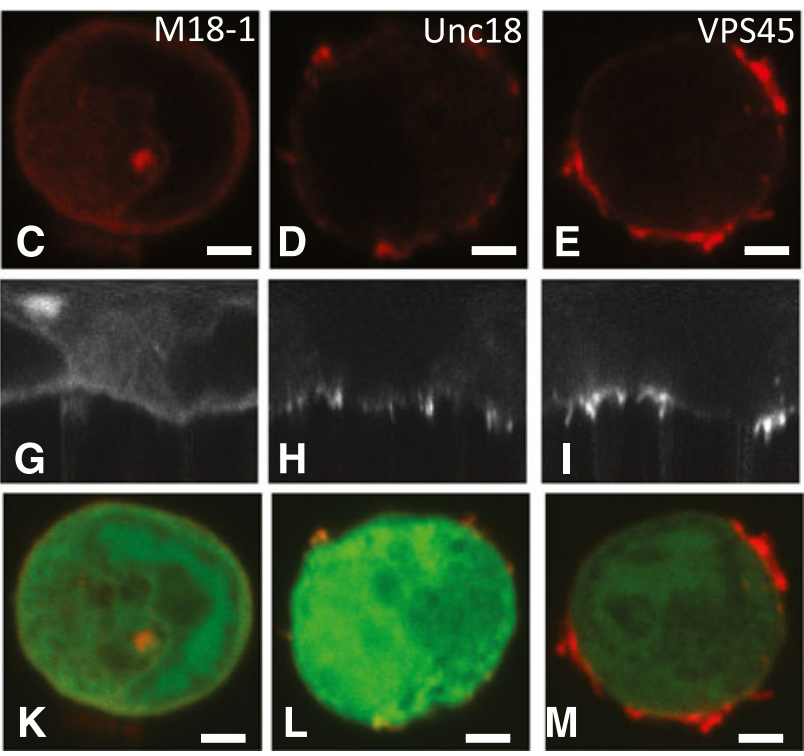

N
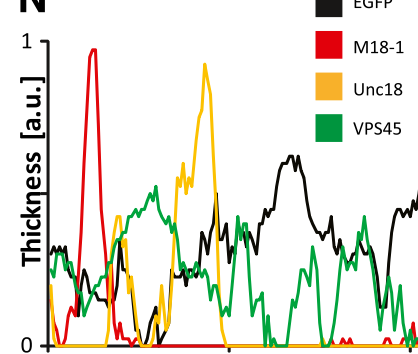

0

60

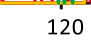

120

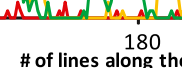

80

Fig. 2 Role of SM proteins in the vesicle cycle and in the regulation of cortical F-actin in chromaffin cells. a Cartoon model of SM proteins in intracellular vesicle trafficking pathways. The Sly1p subfamily is involved in the transport of secretory vesicles between the endoplasmatic reticulum $(E R)$, which is attached to the nucleus $(N u)$, and the Golgi apparatus $(G A)$, whereas members of the VPS33p subfamily participate in the vesicle transport to vacuoles ( $\mathrm{Vac}$ ) or lysosomes $(\mathrm{Lys})$. The VPS45p subfamily regulates endosomal $(E n)$ vesicle trafficking, and members of the Sec1p family (e.g., Rop in D. melanogaster, Unc18 in C. elegans, and Munc18 in mammals) are essential for regulated secretion. Visualization of cortical F-actin in chromaffin cells. The images show typical examples of Munc18-1 null chromaffin cells after expression of either EGFP alone (b) as control or the SM proteins Munc18-1 (c), Unc18 (d), and VPS45

VPS33p Family The VPS33p subfamily of SM proteins was first shown to regulate the vesicle transport to vacuoles (Banta et al. 1990) and has an additional function in vesicle-trafficking processes between the late Golgi and the endosome (Subramanian et al. 2004). It was shown that VPS33p interacts with the endosomal syntaxin Pep12, which was previously identified as a binding protein of the SM protein VPS45 (Cowles et al. 1997). This is the only demonstrated interaction between an individual syntaxin and two SM proteins at the same organelle. Furthermore, VPS33 was found to be involved in the transport of endocytosed vesicles to lysosomes (Akbar et al. 2009). (e). Acute expression of SM genes was induced with Semliki Forest virus (SFV) from a bicistronic message containing a poliovirus internal ribosomal entry site and EGFP. $\mathbf{f}-\mathbf{i}$ Confocal images of $\mathbf{b}-\mathbf{e}$ after polar transformation. $\mathbf{j}-\mathbf{m}$ Confocal images showing the successful SFV infection of the chromaffin cells, since all SM proteins were coexpressed with EGFP to identify infected chromaffin cells. n Visualization of typical examples of cortical F-actin thickness along the plasma membrane in Munc18-1 null chromaffin cells which express EGFP or SM proteins. o Quantification of average thickness of the cortical F-actin in Munc18-1 null chromaffin cells which express EGFP or SM proteins. For all conditions, $n=5$ and the error bars display the SEM. ${ }^{*} p<0.05, * * * p<0.001$ by Student's $t$ test compared to EGFP controls. Scale bars, $2 \mu \mathrm{m}$

\section{Preliminary Data}

In order to analyze whether SM proteins, other than Munc18-1, affect the cortical F-actin network in chromaffin cells, we performed pilot experiments. We infected adrenal chromaffin cells from embryonic Munc18-1 null mice with Semliki Forest virus constructs of the SM proteins Unc18 and VPS45. The cultured chromaffin cells were fixed with $4 \%$ paraformaldehyde (PFA) at DIV3 (6 h after the viral infection), and the cortical F-actin was stained with rhodaminephalloidin. Images were acquired with confocal microscopy and analyzed with our newly developed quantification 
method. We determined whether the overexpression of the two described SM proteins, participating in different intracellular vesicle-trafficking processes (Unc18, vesicle transport to plasma membrane; VPS45, vesicle transport to lysosomes and endosomes), leads to alterations in the cortical F-actin which are similar to the changes we observed after the overexpression of Munc18-1.

Our preliminary results show that both SM proteins can regulate the thickness of cortical F-actin in chromaffin cells, independently from the pathways in which they are known to participate in. As shown in Fig. 2b, the rhodaminephalloidin staining of Munc18-1 null chromaffin cells expressing enhanced green fluorescent protein (EGFP) shows a similar thick cortical F-actin network as uninfected controls described previously (Toonen et al. 2006 and Fig. 1). The overexpression of the SM proteins Munc18-1, Unc18, and VPS45 via Semliki Forest virus infection resulted in a decrease in cortical F-actin, as shown in Fig. 2c-e. This effect is reflected in the transformed images (Fig. 2f-i) as well as in the graphs in Fig. 2m, n. Typical examples of the cortical F-actin distribution along the plasma membrane in all four conditions are visualized in Fig. $2 \mathrm{~m}$. The average thickness of the network, dependent on the presence of the described SM proteins, is shown in Fig. 2n. It becomes clear that the overexpression of wild type Munc18-1 led to the strongest effect ( $35 \%$ reduction in F-actin thickness) and a complete rescue of the Munc18-1 null phenotype. The decrease in cortical F-actin thickness, observed after the overexpression of Unc18 (35\% reduction in F-actin thickness), is similar to the effect of overexpression of wild type Munc18-1. This result can be expected, since Unc18 is closely related to its mammalian ortholog Munc18-1 (amino acid sequence homology to Munc18-1 according to Clustal alignment, 57 \%). Furthermore, Unc18 is known to be involved in the secretory vesicle trafficking to the plasma membrane and essential for the docking process. Surprisingly, the overexpression of the SM protein VPS45 (amino acid sequence homology to Munc18-1 according to Clustal alignment, $18 \%$ ), which is important for vesicle transport to lysosomes and endosomes, seems to have a regulating effect on the cortical F-actin (11\% reduction in F-actin thickness) as well. However, compared to the overexpression of Munc18-1 wild type or Unc18, the rescue of the phenotype observed in Munc18-1 null chromaffin cells was less prominent after the overexpression of VPS45.

\section{Discussion and Perspectives}

In our review, we describe the well-known role of Munc181 in docking of secretory vesicles to the plasma membrane and its unresolved function in the regulation of cortical Factin in chromaffin cells. In addition, we shortly discuss the previously used F-actin quantification methods in comparison to our novel analysis algorithm. In earlier studies, overall changes in the cortical F-actin network, due to stimulation or genetic manipulations, were determined and presented as the percentage of cells with altered cortical F-actin. However, with our newly developed quantification method, we are able to analyze the localization and distribution of F-actin along the plasma membrane in a more detailed fashion. This method, together with immunohistochemistry approaches, allows us to also investigate colocalization of $\mathrm{F}$-actin patches and actin-regulating proteins, which will help to unravel the function of Munc18-1 in the regulation of this subplasmalemmal network. One way to investigate the molecular mechanism that underlies this process is to analyze whether Munc18-1 orthologs, which belong to the SM protein family, show the same ability as Munc18-1 to rescue the Munc18-1 null phenotype by decreasing the cortical F-actin network to the level of Munc18-1 wild type. The four subfamilies of this protein family are shortly described in this review. In order to test their F-actin-regulating function, we overexpressed two SM proteins in chromaffin cells with a Munc18-1 null background, one which participates in the vesicle trafficking to the plasma membrane (Unc18) and one which is involved in vesicle transport to lysosomes and endosomes (VPS45). Both SM proteins are able to downregulate the thick cortical F-actin network that we observe in Munc18-1 null chromaffin cells. However, the rescue effect on the F-actin thickness after the expression of Unc18 or VPS45 is not as dramatic as after the expression of wild type Munc18-1. The only common domain of all SM proteins is the Sec1 like domain. However, this is not enough to explain our observations, since the amino acid sequences of the SM proteins in this domain show a great variability. We believe that an elaborate sequence and domain analysis might be one way to understand the function of SM proteins in the regulation of F-actin. There is no evidence for a direct interaction of this protein family and the cytoskeletal component, but there are hints that point to distinct pathways. One interesting observation by Morgera et al. (2011) showed that the yeast SM protein Sec1 can directly bind to proteins of the exocyst complex and that exocyst subunits interact with the yeast ortholog of myosin V, Myo2 (Jin et al. 2011). This finding, like our observations, links essential parts of the secretory machinery to components of the cytoskeleton. Another observation connects the SM protein VPS45 to Rab27, which was shown to operate in a complex with myosin Va, which in turn interacts directly with actin filaments (Fukuda 2003). Further experimental efforts will be necessary to unravel the exciting new connection between SM proteins and subplasmalemmal actin cytoskeleton. 
Acknowledgments This work was supported by grants from Netherlands Organization for Scientific Research, NWO (VENI 916-36-043), and the European Union Seventh Framework Programme under grant agreement FP7-People-ITN-2008-238055 ("BrainTrain" project). We would like to thank Matthijs Verhage for the fruitful discussions and Jens Weber and Rhiannon Meredith for the critical comments on the manuscript.

Open Access This article is distributed under the terms of the Creative Commons Attribution License which permits any use, distribution, and reproduction in any medium, provided the original author(s) and the source are credited.

\section{References}

Akbar MA, Ray S, Krämer H (2009) The SM protein Car/Vps33a regulates SNARE-mediated trafficking to lysosomes and lysosome-related organelles. Mol Biol Cell 20:1705-1714

Aunis D, Bader MF (1988) The cytoskeleton as a barrier to exocytosis in secretory cells. J Exp Biol 139:253-266

Bhagavathi S, Malathi R (1996) Introns and protein revolution - an analysis of the exon/intron organisation of actin genes. FEBS Lett 1:63-65

Banta LM, Vida TA, Herman PK, Emr SD (1990) Characterization of yeast VPS33p, a protein required for vacuolar sorting and vacuole biogenesis. Mol Cell Biol 10:4638-4649

Barclay JW (2008) Munc18-1 regulates the inital release rate of exocytosis. Biophys J 94:1084-1093

Bassham DC, Sanderfoot AA, Kovaleva V, Zheng H, Raikhel NV (2000) At VPS45 complex formation at the trans-Golgi network. Mol Biol Cell 11:2251-2265

Burkhardt P, Hattendorf DA, Weis WI, Fasshauer D (2008) Munc18a controls SNARE assembly through its interaction with the syntaxin N-peptide. EMBO J 27:923-933

Chieregatti E, Witkin JW, Baldini G (2002) SNAP-25 and synaptotagmin 1 function on $\mathrm{Ca}^{2+}$-dependent reversible docking of granules to the plasma membrane. Traffic 3:496-511

Cowles CR, Snyder WB, Burd CG, Emr SD (1997) Novel Golgi to vacuole delivery pathway in yeast: identification of a sorting determinant and required transport component. EMBO J 16:2769-2782

De Wit H, Cornelisse LN, Toonen RF, Verhage M (2006) Docking of secretory vesicles is syntaxin dependent. PLoS One 1:e126

De Wit H, Walter AM, Gulyás-Kovács A, Riedel D, Sørensen JB, Verhage M (2009) Synaptotagmin-1 docks secretory vesicles to syntaxin1/SNAP25 acceptor complexes. Cell 138:935-946

De Wit H (2010a) Molecular mechanism of secretory vesicle docking. Biochem Soc Trans 38:192-198

De Wit H (2010b) Morphological docking of secretory vesicles. Histochem Cell Biol 134:103-113

Doreian BW, Fulop TG, Smith CB (2008) Myosin II activation and actin reorganization regulate the mode of quantal exocytosis in mouse adrenal chromaffin cells. J Neuroscience 28:4470-4478

Doussau F, Augustine GJ (2000) The actin cytoskeleton and neurotransmitter release: an overview. Biochimie 82:353-363

Dulubova I, Suqita S, Hill S, Hosaka M, Fernandez I, Südhof TC, Rizo J (1999) A conformational switch in syntaxin during exocytosis: role of munc18. EMBO J 18:4372-4382

Dulubova I, Yamaguchi T, Gao Y et al (2002) How Tlg2p/syntaxin16 "snares" VPS45. EMBO J 21:3620-3631

Dulubova I, Khvotchev M, Liu S, Hurveya I, Südhof TC, Rizo J (2007) Munc18-1 binds directly to the neuronal SNARE complex. Proc Natl Acad Sci USA 104:2697-2702

Fukuda M (2003) Slp4-a/granuphilin-a inhibits dense-core vesicle exocytosis through interaction with the GDP-bound form of Rab27A in PC12 cells. J Biol Chem 278:15390-15396
Furgason MLM, MacDonald C, Shanks SG, Ryder SP, Bryant NJ, Munson M (2009) The N-terminal peptide of the syntaxin Tlg2p modulates binding of its closed conformation to Vps45p. PNAS 106:14303-14308

Gerber SH, Rah JG, Min SW et al (2008) Conformational switch of syntaxin-1 controls synaptic vesicle fusion. Science 321:15071510

Gulyás-Kovács A, de Wit H, Milosevic I, Kochubey O, Toonen R, Klingauf J, Verhage M, Sørensen JB (2007) Munc18-1: sequential interactions with the fusion machinery stimulate vesicle docking and priming. J Neurosci 27:8676-8686

Hata Y, Südhof TC (1995) A novel ubiquitous form of Munc18 interacts with multiple syntaxins. Use of the yeast two-hybrid system to study interactions between proteins involved in membrane traffic. J Biol Chem 270:13022-13028

Jin Y, Sultana A, Gandhi P (2011) Myosin V transports secretory vesicles via a Rab GTPase cascade and interaction with the exocyst complex. Dev Cell 21:1156-1170

Khvotchev M, Dulubova I, Sun J, Dai H, Rizo J, Südhof TC (2007) Dual modes of Munc18-1/SNARE interactions are coupled by functionally critical binding to syntaxin-1N-terminus. J Neurosci 27:12147-12155

Kosodo Y, Noda Y, Adachi H, Yoda K (2002) Binding of Sly1 to Sed5 enhances formation of the yeast early Golgi SNARE complex. J Cell Sci 115:3683-3691

Li Y, Gallwitz D, Peng R (2005) Structure-based functional analysis reveals a role for the SM protein Slylp in retrograde transport to the endoplasmatic reticulum. Mol Biol Cell 16:3951-3962

Morgera F, Sallah MR, Dubuke ML et al (2011) Regulation of exocytosis by the exocyst subunit Sec6 and the SM protein Sec1. Mol Biol Cell 23:337-346

Novick P, Ferro S, Schekman R (1981) Order of events in the yeast secretory pathway. Cell 25:461-469

Pevsner J, Hsu SC, Scheller RH (1994) n-Sec1: a neural-specific syntaxin-binding protein. Proc Natl Acad Sci USA 91:14451449

Rickman C, Archer DA, Meunier FA, Craxton M, Fukuda M, Burgoyne RD, Davletov B (2004) Synaptotagmin interaction with the syntaxin/SNAP-25 dimer is mediated by an evolutionarily conserved motif and is sensitive to inositol hexakisphosphate. $\mathrm{J}$ Biol Chem 279:12574-12579

Schiavo G, Stenbeck G, Rothman JE, Söllner TH (1997) Binding of the synaptic vesicle v-SNARE, synaptotagmin, to the plasma membrane t-SNARE, SNAP-25, can explain docked vesicles at neurotoxin-treated synapses. Proc Natl Acad Sci USA 94:997-1001

Schulze KL, Littleton JT, Salzberg A et al (1994) Rop, a Drosophila homolog of yeast Sec1 and vertebrate n-Sect/Munc-18 proteins, is a negative regulator of neurotransmitter release in vivo. Neuron 13:1099-1108

Søgaard M, Tani K, Ye RR et al (1994) A Rab protein is required for the assembly of SNARE complexes in the docking of transport vesicles. Cell 78:937-948

Söllner T, Whiteheart SW, Brunner M, Erdjument-Bromage H, Geromanos S, Tempst P, Rothman JE (1993) SNAP receptors implicated in vesicle targeting and fusion. Nature 362:318323

Struthers MS, Shanks SG, MacDonald C et al (2009) Functional homology of mammalian syntaxin 16 and yeast $T \lg 2 \mathrm{p}$ reveals a conserved regulatory mechanism. J Cell Sci 122:2292-2299

Subramanian S, Woolford CA, Jones EW (2004) The Sec1/Munc18 protein, VPS33p, functions at the endosome and the vacuole of Saccharomyces cerevisiae. Mol Biol Cell 15:2593-2605

Tellam JT, McIntosh S, James DE (1995) Molecular identification of two novel Munc18-isoforms expressed in non-neuronal tissues. J Biol Chem 270:5857-5863 
Tellam JT, James DE, Stevens TH, Piper RC (1997) Identification of a mammalian Golgi Sec1p-like protein, mVps45. J Biol Chem 272:6187-6193

Toonen RF, Verhage M (2003) Vesicle trafficking: pleasure and pain from SM genes. Trends Cell Biol 13:177-186

Toonen RF, Kochubey O, de Wit $\mathrm{H}$ et al (2006) Dissecting docking and tethering of secretory vesicles at the target membrane. EMBO J 25:3725-3737

Trifaró JM, Rodriguez Del Castillo A, Vitale ML (1992) Dynamic changes in chromaffin cell cytoskeleton as prelude to exocytosis. Mol Neurobiol 6:339-358

Trifaró JM, Rosé SD, Lejen T, Elzagallaai A (2000) Two pathways control chromaffin cortical F-actin dynamics during exocytosis. Biochimie 82:339-353

Trifaró JM, Gasman S, Gutiérrez LM (2008) Cytoskeletal control of vesicle transport and exocytosis in chromaffin cells. Acta Physiol 192:165-172

Tschopp J, Esmon PC, Schekman R (1984) Defective plasma membrane assembly in yeast secretory mutants. J Bacteriol 160:966-970
Verhage M, Sørensen JB (2008) Vesicle docking in regulated exocytosis. Traffic 9:1414-1424

Vitale ML, Seward EP, Trifaró JM (1995) Chromaffin cell cortical actin network dynamics control the size of the release-ready vesicle pool and the initial rate of exocytosis. Neuron 14:353363

Voets T, Toonen RF, Brian EC et al (2001) Munc18-1 promotes large dense-core vesicle docking. Neuron 31:581-591

Webb GC, Hoedt M, Poole LJ, Jones EW (1997) Genetic interactions between a pep7 mutation and the PEP12 and VPS45 genes: evidence for a novel SNARE component in transport between the Saccharomyces cerevisiae Golgi complex and endosome. Genetics 147:467-478

Weimer RM, Richmond JE, Davis WS, Hadwiger G, Nonet ML, Jorgensen EM (2003) Defects in synaptic vesicle docking in unc-18 mutants. Nat Neurosci 6:1023-1030

Yamaguchi T, Dulubova I, Min SW, Chen X, Rizo J, Südhof TC (2002) Sly1 binds to Golgi and ER syntaxins via a conserved N-terminal peptide motif. Dev Cell 2:295-305 